\title{
Characterization of the superoxide dismutase SOD1 gene of Kluyveromyces marxianus L3 and improved production of SOD activity
}

\author{
S. Raimondi • D. Uccelletti $\cdot$ D. Matteuzzi • \\ U. M. Pagnoni • M. Rossi • C. Palleschi
}

Received: 12 July 2007 /Revised: 30 October 2007 / Accepted: 31 October 2007 / Published online: 27 November 2007

(C) Springer-Verlag 2007

\begin{abstract}
Superoxide dismutase (SOD) activity is one major defense line against oxidative stress for all of the aerobic organisms, and industrial production of this enzyme is highly demanded. The $\mathrm{Cu} / \mathrm{Zn}$ superoxide dismutase gene (KmSOD1) of Kluyveromyces marxianus L3 was cloned and characterized. The deduced KmSod1p protein shares $86 \%$ and $71 \%$ of identity with Kluyveromyces lactis and Saccharomyces cerevisiae Sod1p, respectively. The characteristic motifs and the amino acid residues involved in coordinating copper and zinc and in enzymatic function were conserved. To the aim of developing a microbial production of $\mathrm{Cu} / \mathrm{Zn}$ superoxide dismutase, we engineered the K. marxianus $\mathrm{L} 3$ strain with the multicopy plasmid YGKmSOD1 harboring the KmSOD1 gene. The production of KmSOD1p in $K$. marxianus L3 and $K$. marxianus L3 (pYG-KmSOD1) in response to different compositions of the culture medium was evaluated. The highest specific
\end{abstract}

Electronic supplementary material The online version of this article (doi:10.1007/s00253-007-1270-8) contains supplementary material, which is available to authorized users.

S. Raimondi • U. M. Pagnoni $\cdot$ M. Rossi

Department of Chemistry,

University of Modena and Reggio Emilia,

Modena, Italy

D. Uccelletti • C. Palleschi $(\bowtie)$

Department of Developmental and Cell Biology,

University of Rome "La Sapienza",

Piazza Aldo Moro 5,

00185 Rome, Italy

e-mail: claudio.palleschi@uniroma1.it

D. Matteuzzi

Department of Pharmaceutical Science, University of Bologna,

Bologna, Italy activity (472 $\mathrm{U}_{\mathrm{SOD}} \mathrm{mg}_{\mathrm{prot}}{ }^{-1}$ ) and the highest volumetric yield $\left(8.8 \times 10^{5} \mathrm{U}_{\mathrm{SOD}} 1^{-1}\right)$ were obtained by the recombinant strain overexpressing KmSODl in the presence of $\mathrm{Cu}^{2+}$ and $\mathrm{Zn}^{2+}$ supplements to the culture media. The best performing culture conditions were positively applied to a laboratory scale fed-batch process reaching a volumetric yield of $1.4 \times 10^{6} \mathrm{U}_{\mathrm{SOD}} 1^{-1}$.

Keywords Kluyveromyces marxianus .

$\mathrm{Cu} / \mathrm{Zn}$ superoxide dismutase $\cdot$ Expression $\cdot$ Productivity

\section{Introduction}

Superoxide dismutases (SOD, EC 1.15.1.1) catalyze the dismutation of superoxide anions $\left(\mathrm{O}_{2}^{\circ-}\right)$ into oxygen and hydrogen peroxide. They are metalloenzymes and represent an important antioxidant defense in nearly all aerobic and aerotolerant organisms, which evolved mechanisms to prevent or repair oxidative damages caused by oxygen exposure (Fridovich 1978). The superoxide anion is a byproduct of enzymatic and non-enzymatic reactions involved in metabolic processes, such as oxidative phosphorylation and photosynthesis (Fridovich 1998), which can cause peroxidation of membrane fatty acid, protein oxidation, and DNA modification. The damages are generated by direct or indirect reactions: In fact, in the presence of $\mathrm{Fe}^{3+}, \mathrm{H}_{2} \mathrm{O}_{2}$, and ${ }^{\circ} \mathrm{NO}$, a superoxide anion can produce other reactive oxygen species (ROS) with high oxidizing potential and enhanced toxicity (Wink and Mitchell 1998).

Considerable experimental evidence has been accumulated on the therapeutical applications of SOD including prevention of oncogenesis (Nishikawa et al. 2001), treatment of inflammatory diseases, and arthritis (Corvo et al. 2002; Zhang et al. 2002), of infections (Emerit et al. 2006), 
and of ischemic or burn injuries for tissue protection (Vorauer-Uhl et al. 2001; Yabe et al. 2001; Yunoki et al. 2003).

At present, SOD is produced by extraction from animal tissues, mostly bovine liver or erythrocytes. A microbial production process could represent a significant improvement in terms of yields, costs, and product safety. Several attempts to produce the enzyme utilizing Escherichia coli or yeasts have indeed been performed (Yoo et al. 1999; Goulielmos et al. 2003; Yu 2007).

In a recent study, the feasibility of a yeast fermentative production of SOD was explored (Dellomonaco et al. 2007). The screening of "generally recognized as safe" yeasts belonging to different genus and species pointed out Kluyveromyces marxianus $\mathrm{L} 3$ as a high SOD producer. The dairy yeast $K$. marxianus, besides the high SOD activity, presents a number of gainful large scale fermentation characteristics in comparison to other yeast species: fast and high biomass yield, high temperature of growth, and safety (not methylotrophic and food grade status) (Fonseca et al. 2007; Limtong et al. 2007). In addition, it is a Crabtree-negative yeast, with the capability to grow on a large variety of carbon sources, including whey, inuline, and pectine (Bender et al. 2006; Masoud and Jespersen 2006).

Yeast cells produce two forms of superoxide dismutase: the copper- and zinc-containing SOD $(\mathrm{Cu} / \mathrm{Zn} \mathrm{SOD})$, encoded by SOD1 gene, which is the predominant form and protects cytosolic constituents from oxidation (MoradasFerreira et al. 1996; Sturtz et al. 2001), and the manganesecontaining enzyme (Mn SOD), encoded by the gene SOD2, which is located in the mitochondrial matrix (Luk et al. 2005; Moradas-Ferreira et al. 1996).

In this work, we report the characterization of the superoxide dismutase SOD1 gene of $K$. marxianus. To improve SOD productivity, the $K$. marxianus $\mathrm{L} 3$ strain was engineered by increasing the gene dosage of SOD1. Specific activity and volumetric productivity were studied in batch cultures of wild-type and recombinant $K$. marxianus L3 cultures by varying media composition, carbon sources, and metal cofactor availability.

\section{Materials and methods}

Biochemicals and reagents

All chemicals, unless otherwise specified, were provided by Sigma-Aldrich (Steinheim, Germany). The Ex-Taq kit used for polymerase chain reaction (PCR) reactions was supplied by TaKaRa (Otsu, Higa, Japan). The other enzymes and the reagents used for molecular biological procedures were from Roche. Primers were supplied by MWG-Biotech
(Ebersberg, Germany). Microbiological products were purchased from Difco Laboratories (Sparks, MD, USA).

Strains and growth conditions

Kluyveromyces marxianus L3 (Dellomonaco et al. 2007) was the source of genomic DNA for the isolation of the $\mathrm{Cu} / \mathrm{Zn}$ superoxide dismutase gene (SODl) and was used as homologous expression host. Yeast cells were grown in YPD (consisting of yeast, peptone, and dextrose) medium (10 $\mathrm{g} \mathrm{l}^{-1}$ yeast extract, $10 \mathrm{~g} \mathrm{l}^{-1}$ peptone, and $20 \mathrm{~g} \mathrm{l}^{-1}$ glucose). Supplement of antibiotic G418 $\left(0.2 \mathrm{~g} \mathrm{l}^{-1}\right)$ was added for the maintenance of recombinant plasmids.

The yeast strains Saccharomyces cerevisiae BY4741 (MAT a his3 leu2 met15 ura3) and Kluyveromyces lactis MW98-8C (MATo ura A arg-lys) were used to prepare cell extracts to assess the antibody specificity for yeasts $\mathrm{Cu} / \mathrm{Zn}$ superoxide dismutases.

Escherichia coli $\mathrm{DH} 5 \alpha(\varphi 80$ lacZ $\Delta M 15$, recA1, end A1, gyr A96, thi-1, hsd R17, rel A1) was used for general cloning purposes and was grown at $37^{\circ} \mathrm{C}$ in Luria broth. Ampicillin was utilized to select $E$. coli transformants at $0.1 \mathrm{~g}^{-1}$. 5-Bromo-4-chloro-3-indolyl- $\beta$-D-thiogalactopyranoside (X-gal) was utilized at concentrations of $0.04 \mathrm{~g} \mathrm{l}^{-1}$.

DNA isolation and manipulation

A 10-ml culture was grown overnight in YPD broth to isolate $K$. marxianus L3 chromosomal DNA according to the method described by Sherman et al. (1986).

DNA manipulations were carried out under the conditions specified by the manufacturer or according to standard procedures as described by Sambrook et al. (2001).

DNA fragments from agarose gel were purified using the QIAquick Kit (Qiagen, Valencia, CA, USA).

\section{PCR amplification}

The entire SOD1 coding region was amplified from $K$. marxianus L3 genome using the couple of degenerated primers DegSOD1-for (AAGCTTATGGTTMATGCAG TYGCAGTK) and DegSOD1-rev (AAGCTTTTAGTTRG AKAKACCAATRACA), designed on the basis of $K$. lactis NRRL Y-1140 (XM_454197) and S. cerevisiae S288C SOD1 (NC_001142) sequences alignment. Both $5^{\prime}$ and $3^{\prime}$ oligonucleotide primers contained the recognition site for the restriction endonuclease HindIII (underlined).

DNA amplification was performed using a thermocycler (Robocycler Gradient 96, Biorad, La Jolla, CA, USA) programmed with the following temperature profile: $94^{\circ} \mathrm{C}$ for $5 \mathrm{~min}(1 \mathrm{cycle}) ; 94^{\circ} \mathrm{C}$ for $1 \mathrm{~min}, 55^{\circ} \mathrm{C}$ for $1 \mathrm{~min}$, and $72^{\circ} \mathrm{C}$ for $1 \mathrm{~min}(30$ cycles $)$ and $72^{\circ} \mathrm{C}$ for $7 \mathrm{~min}$ ( 1 cycle). 
Plasmid construction and transformation

The PCR fragment encoding the SOD1 gene was ligated within pCR2.1-TOPO vector (Invitrogen, USA) according to the manufacturer instructions, giving pCR-KmSOD1.

The gene was excised from pCR-KmSOD1 by HindIII digestion and ligated into the vector pYG131 linearized with HindIII and dephosphorylated. pYG131 derives from the plasmid pKD1 (Chen et al. 1986; Saliola et al. 1999) and carries the gene for the resistance to antibiotic G418. In the resulting plasmid pYG-KmSOD1, the gene SOD1 was under the control of the $K$. lactis KlADH4 inducible promoter and of the $K$. lactis $P G K$ terminator.

Plasmids were transformed into E. coli $\mathrm{DH} 5 \alpha$ competent cells (Sambrook et al. 2001). K. marxianus L3 was transformed by electroporation with a Biorad Gene-Pulser apparatus, as described by Wesolowsky-Louvel et al. (1996).

\section{Shake-flask cultivation}

To determine SOD activity, $K$. marxianus L3 and $K$. marxianus L3 harboring pYG-KmSOD1 were aerobically grown in $25 \mathrm{ml}$ of complex media YP $\left(10 \mathrm{~g} \mathrm{l}^{-1}\right.$ yeast extract, $10 \mathrm{~g}^{-1}$ peptone) or minimal media YKK $\left(6.7 \mathrm{~g} \mathrm{l}^{-1}\right.$ yeast nitrogen base without amino acids, $8.5 \mathrm{~g} \mathrm{l}^{-1} \mathrm{KH}_{2} \mathrm{PO}_{4}$ and $3.4 \mathrm{~g} \mathrm{l}^{-1} \quad \mathrm{~K}_{2} \mathrm{HPO}_{4}$ ) containing glucose (YPD and YKKD), glycerol (YPG and YKKG), or lactose (YPL and YKKL). Carbon source solutions were filtered through a $0.22-\mu \mathrm{m}$ pore-size filter and added to the sterile basal medium at the final concentration of $20 \mathrm{~g}^{-1}$.

For the maintenance of the expression plasmid pYGKmSOD1, YP and YKK media contained $0.2 \mathrm{~g} \mathrm{l}^{-1}$ and $0.3 \mathrm{~g} \mathrm{l}^{-1}$ of $\mathrm{G} 418$, respectively.

To evaluate the effect of the metal cofactors, SOD specific activity in cultures non-supplemented or supplemented with $0.1 \mathrm{mM} \mathrm{CuCl}_{2}$ and $0.1 \mathrm{mM} \mathrm{ZnCl} 2$ was compared.

The flask were inoculated $(10 \% v / v)$ with exponential phase pre-cultures grown in the same medium and placed in an orbital shaking incubator $(180 \mathrm{rpm})$ at $30^{\circ} \mathrm{C}$ for $48 \mathrm{~h}$. Induction with $2 \% v / v$ of ethanol was performed after $24 \mathrm{~h}$ of growth.

Fed-batch cultivation

Functional SOD expression was studied in fed-batch experiments performed in a Sixfors bioreactor (Infors AG, Bottmingen, Switzerland). Vessels of 0.5-1 working volume were equipped with InPro6820 and 405-DPAS probes (Mettler Toledo, Switzerland) for the continuous measurement of dissolved oxygen concentration (expressed as percentage saturation) and $\mathrm{pH}$, respectively. Temperature was kept at $30^{\circ} \mathrm{C}$, stirring at $1,000 \mathrm{rpm}$ and air flow at
$0.5 \mathrm{v} / \mathrm{v} / \mathrm{m}$ (volume per volume per minute). To prevent nutrient limitation, YPG medium was supplemented with $0.5 \mathrm{~g} \mathrm{l}^{-1} \mathrm{MgSO}_{4}, 8.0 \mathrm{~g} \mathrm{l}^{-1} \mathrm{KH}_{2} \mathrm{PO}_{4}, 0.1 \mathrm{mM} \mathrm{CuCl}_{2}$, and $0.1 \mathrm{mM} \mathrm{ZnCl}_{2}$. The medium after addition of $0.2 \mathrm{~g} \mathrm{l}^{-1}$ G418, was inoculated $(10 \% v / v)$ with exponential phase seed-cultures of $K$. marxianus L3(pYG-KmSOD1), grown in the same medium. Foaming was controlled by the initial addition of PPG2000 (Cyanamid, Catania, Italy) at the concentration of $0.5 \mathrm{~g} \mathrm{l}^{-1}$. Feeding rate of $0.5 \mathrm{ml} \mathrm{h}^{-1}$ of $200 \mathrm{~g} \mathrm{l}^{-1}$ glycerol solution was applied when the batch culture reached the late-exponential phase and the concentration of glycerol decreased below $3.0 \mathrm{~g} \mathrm{l}^{-1}$. Induction of KmSOD1 expression was obtained with the addition of ethanol to a final concentration of $2 \% v / v$. Culture samples were collected during batch and feeding phase to estimate biomass yield, substrate consumption and SOD activity.

Preparation of cell-free extracts

Biomass was harvested by centrifugation $(5,000 \times g$ for $10 \mathrm{~min}$ at $4^{\circ} \mathrm{C}$ ), washed twice in potassium phosphate buffer $\mathrm{pH} 7.8,50 \mathrm{mM}$; ethylenediaminetetraacetic acid $0.1 \mathrm{mM}$ and resuspended $1: 1 \mathrm{w} / \mathrm{v}$ in the same buffer. Cells were disrupted for $30 \mathrm{~min}$ at $4^{\circ} \mathrm{C}$ by using $0.5 \mathrm{~mm}$ glass beads (Sigma Aldrich, cat. no. G8772) in a vibration homogenizer at $1,800 \mathrm{rpm}$. Whole cells and debris were removed by centrifugation at $13,000 \times g$ for $15 \mathrm{~min}$ at $4^{\circ} \mathrm{C}$. Protein concentration of the cell-free extract was assayed according to Lowry (Lowry et al. 1951) using bovine serum albumin as standard.

\section{Superoxide dismutase activity}

SOD activity was assayed by measuring the enzymatic inhibition of cytochrome $c$ reduction, as described by McCord and Fridovich (McCord and Fridovich 1969). One unit of superoxide dismutase was defined as the amount of enzyme that inhibited the reduction of cytochrome $c$ by $50 \%$ in a coupled system, using xanthine and xanthine oxydase to generate superoxide anion at $\mathrm{pH} 7.8$ and $25^{\circ} \mathrm{C}$.

To determine Mn-SOD activity, $\mathrm{Cu} / \mathrm{Zn}$-SOD was inactivated by adding $30 \mathrm{mM} \mathrm{KCN}$ to the samples. $\mathrm{Cu} / \mathrm{Zn} \mathrm{SOD}$ activity was calculated as the difference between total and Mn SOD activities.

Specific activity of cell-free extracts was expressed as enzymatic units per milligram of total proteins.

Western-blot analysis of $\mathrm{Cu} / \mathrm{Zn} \mathrm{SOD}$

Proteins $(20 \mu \mathrm{g} / \mathrm{lane})$ of each cell-free extracts were separated in sodium dodecyl sulfate polyacrylamide gel electrophoresis using the buffer system of Laemmli 
(Laemmli 1970) and 12\% acrylamide gels. The gels were then electroblotted onto a polyvinylidene difluoride membrane (Biorad). Proteins were detected with polyclonal rabbit antibodies raised against rat $\mathrm{Cu} / \mathrm{Zn}$ SOD (Stressgene, Victoria, Canada) in dilution 1:1,000. The secondary antibodies were monoclonal anti-rabbit IgG conjugated with peroxidase (Promega). Immunologically active proteins were visualized with the electrochemiluminescence detection system (Amersham) according to the manufacturer's instructions.

DNA sequencing and sequence analysis

Sequencing service was supplied by MWG-Biotech (Ebersberg, Germany). The DNA sequence data were submitted to the GenBank nucleotide databases under the accession number AM748536.

The nucleotide sequence of K. marxianus L3 SOD1 was analyzed with the discontinuous Mega BLAST program [National Centre for Biotechnology Information (http:// www.ncbi.nlm.nih.gov/BLAST]).

The protein sequence alignment was performed by using the ClustalW program at the Biology Workbench [version 3.2; the San Diego Supercomputer Centre, the University of California, San Diego (http://www.workbench.sdsc.edu)]. The similarity/identity scores were calculated by the opensource freeware MatGAT [version 2.02; Indiana University Biology Archive (http://iubio.bio.indiana.edu/soft/molbio/ evolve/)] (Campanella et al. 2003).

\section{Results}

Characterization of the K. marxianus SOD1 gene

The SOD1-related ORF of $K$. marxianus L3 was amplified by using primers designed on the basis of nucleotide sequences of known SOD1 genes from $K$. lactis and $S$. cerevisiae. The sequences coding for the $\mathrm{N}$ - and $\mathrm{C}$-terminal region of these proteins were highly conserved, and after alignment, degenerated oligomers were designed. Amplification of $K$. marxianus $\mathrm{L} 3$ genomic DNA produced a single DNA band of $0.5 \mathrm{~kb}$ that was cloned into the plasmid pCR2.1-TOPO resulting in pCR-KmSOD1 construct.

The DNA sequences determined from three independent clones were identical and contained one open reading frame (ORF) of $465 \mathrm{bp}$ encoding a putative protein of 154 amino acids with a calculated molecular mass of 15,882 $\mathrm{Da}$ and an isoelectric point of 6.39. The deduced amino acid sequence was compared with the Swiss-Prot protein database. The analysis showed a strong closeness with Sod1p from other yeasts, among them Sod1p of $S$. cerevisiae ( $72 \%$ identity and $82 \%$ of similarity) and the corresponding protein of $K$. lactis ( $86 \%$ of identity and $92 \%$ of similarity). The relationship with human SOD1 was also fairly high $(58 \%$ of identity and $68 \%$ of similarity) (Fig. 1). On the basis of sequence similarities and of activity assays (see later), the ORF was hereinafter named KmSOD1.

The K. marxianus Sod $1 \mathrm{p}$ contained the highly conserved histidine residues $(\mathrm{H}-47, \mathrm{H}-49, \mathrm{H}-64, \mathrm{H}-72, \mathrm{H}-81$, and $\mathrm{H}-121)$ involved in the interaction with the metallic cofactors, which are essential for activity and folding in all the Sod1 enzymes (Hart et al. 1999). In addition, the residues involved in critical interactions were present in the proper positions: these include the aspartic residue D-84 involved in $\mathrm{Cu}^{2+}$ binding, the arginine residue R-144 that participate in leading the substrate to the active site, and the two cysteine residues C-58 and C-147, involved in the formation of a disulfide bond. In the C-terminal region, relevant for the Sod1 activation mechanism (Carroll et al. 2004), KmSodlp presented a glycine in position 143 and a valine in position 145, instead of the conserved residues of serine S-143 and leucine L-145 of mammalian Sod1.

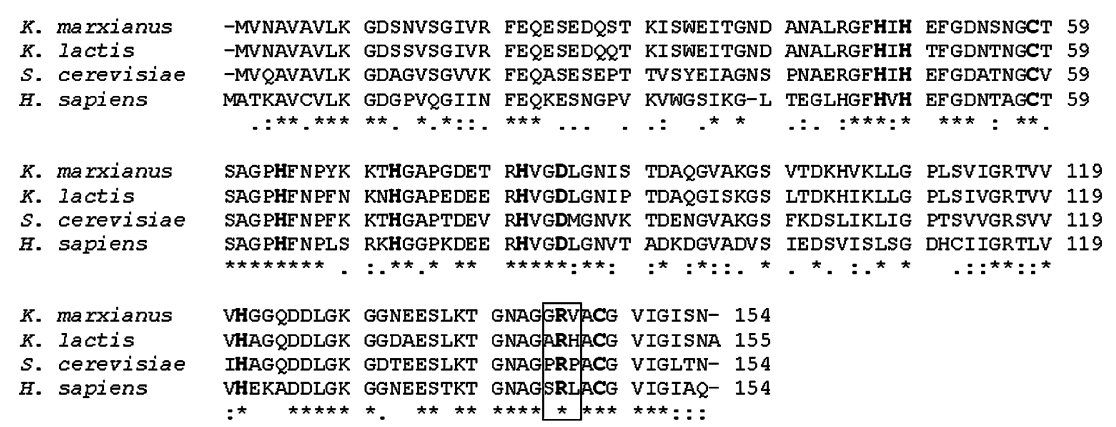

Fig. 1 Alignment of the deduced amino acid sequence of $K$. marxianus $\mathrm{L} 3 \mathrm{Cu} / \mathrm{Zn}$ SOD with other SOD1 sequences: $S$. cerevisiae S288C (CAA89634), K. lactis NRRL Y-1140 (CAG99284), and $H$. sapiens (CAG46542). Asterisk Identical residues in that position of all sequences in the alignment; Colon Conserved substitutions according to Venn diagram (Taylor 1986); Period Semi-conserved substitutions.
Bold letters indicate conserved istidine and aspartic residues for $\mathrm{Cu}$ and $\mathrm{Zn}$ binding, cysteine residues involved in intrachain disulfite bond, arginine residue R-144 leading the substrate to the active site. Amino acid motifs responsible for the $\mathrm{Cu}$ chaperone $\mathrm{CCS}$ independent activation are boxed 
Improvement of $K m \mathrm{SOD} 1$ production

The KmSOD1 gene was introduced in the pYG131 plasmid under the control of the K. lactis ADH4 inducible promoter, resulting in the pYG-KmSOD1 construct. The construct was transformed into $K$. marxianus L3 cells, and the recombinant strain obtained was named $K$. marxianus L3 (pYG-KmSOD1). K. marxianus L3 and K. marxianus L3 (pYG-KmSOD1) were inoculated in YPD; after $24 \mathrm{~h}, 2 \%$ $v / v$ of ethanol was added to culture media to induce protein expression under the control of the KlADH4 promoter. Cultures of $S$. cerevisiae and $K$. lactis were employed as control strains.

After $48 \mathrm{~h}$ of growth, cell-free extracts were analyzed by Western blot; a Coomassie-stained electrophoresis gel of the same samples was used to normalize the proteins (Fig. S1). The experiment established the capability of the antibody to recognize not only ScSodlp (Harris et al. 2005) but also KlSod1p and KmSod1p. The K. marxianus L3 cell extracts presented a single band with the same electrophoretic mobility of ScSodlp and KlSod1p (Fig. 2).

The content of the protein Sod1p in the cell-free extracts of $K$. marxianus L3 was higher when cells were grown in YPG than in YPD. The presence in K. marxianus L3 of the expression vector pYG-KmSOD1 lead to an efficiently increased production of immunologically active Sod1p, as observed in the recombinant strain (Fig. 2).

SOD activity and productivity as a function of growth parameters

Batch cultures of $K$. marxianus L3 and $K$. marxianus L3 (pYG-KmSOD1) were carried out under different growth conditions. SOD specific activity $\left(\mathrm{U}_{\mathrm{SOD}} \mathrm{mg}_{\mathrm{prot}}{ }^{-1}\right)$ and SOD productivity $\left(\mathrm{U}_{\mathrm{SOD}} 1^{-1}\right)$ were compared to evaluate the effect of different media and carbon sources. Complete (YP) and minimal (YKK) media, containing glucose (YPD and YKKD), lactose (YPL and YKKL), or glycerol (YPG and $\mathrm{YKKG}$ ) as carbon source, were tested. Furthermore, SOD activity and productivity were measured in the cultures grown in all the media either non-supplemented or supplemented with $0.1 \mathrm{mM} \mathrm{CuCl}_{2}$ and $0.1 \mathrm{mM} \mathrm{ZnCl}_{2}$.

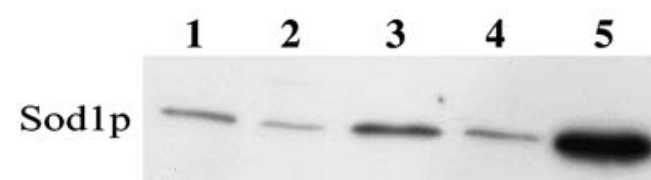

Fig. 2 Western-blot analysis of SOD1p content in the indicated cell cultures. Each well was loaded with $20 \mu \mathrm{g}$ of cell-free extract proteins. Lane 1, S. cerevisiae BY4741 (antibody control); lane 2, K. lactis MW98-8C grown in YPD; lane 3, K. marxianus L3 grown in YPG; lane $4, K$. marxianus $\mathrm{L} 3$ grown in YPD; lane $5, K$. marxianus L3 (pYG-KmSOD1) grown in YPD
The expression of recombinant KmSOD1 was induced with $2 \% v / v$ ethanol after $24 \mathrm{~h}$ of growth. Biomass yield and SOD activity were determined in 48-h cell cultures.

For $K$. marxianus $\mathrm{L} 3$ and $K$. marxianus L3(pYGKmSOD1), only marginal differences in the biomass yields were observed between the various combinations of media and carbon sources. Biomass yields ranged between $5.4 \pm 0.3$ and $6.1 \pm 0.3 \mathrm{~g} \mathrm{DW} \mathrm{1^{-1 }}$. Neither the $\mathrm{Cu}^{2+} / \mathrm{Zn}^{2+}$ supplement nor the presence of the plasmid pYGKmSOD1 affected the biomass yields (Supplementary Table 1).

For K. marxianus L3, SOD specific activity was influenced by medium composition. Maximum specific activity was observed for cells grown on glycerol as carbon source both on complex and minimal media (Fig. 3a,b). The addition of the $\mathrm{Cu}^{2+} / \mathrm{Zn}^{2+}$ supplement to the complex and minimal media produced an overall positive effect on K. marxianus L3 specific activity. All of the cultures supplemented with $0.1 \mathrm{mM} \mathrm{CuCl} 2$ and $0.1 \mathrm{mM} \mathrm{ZnCl} 2$ (indicated with the name of the medium followed by + ) presented higher specific activities than the corresponding ones without the supplement. This was suggestive of a limited availability of $\mathrm{Cu}^{2+} / \mathrm{Zn}^{2+}$ for the optimal functionality of Sod $1 p$ in standard media.

In the absence of the $\mathrm{Cu}^{2+} / \mathrm{Zn}^{2+}$ supplement, the overexpression of recombinant KmSOD1 did not significantly increase the SOD specific activity, and in some cases, a net reduction of the enzymatic activity could be instead observed. However, also for the recombinant cells, the addition of the $\mathrm{Cu}^{2+} / \mathrm{Zn}^{2+}$ supplement resulted in a significant increase of the SOD activity. In some combinations of media and supplement, a consistent improvement of the productive capabilities of the strain was observed. The highest specific activity was obtained in complex medium with glycerol as sole carbon source, with the $\mathrm{Cu}^{2+} / \mathrm{Zn}^{2+}$ supplement ( $\mathrm{YPG}^{\mathrm{rec}}+448.4 \mathrm{U}_{\mathrm{SOD}} \mathrm{mg}_{\text {prot }}{ }^{-1}$ ). For all tested conditions, $\mathrm{Cu} / \mathrm{Zn}$ SOD accounted for more than $95 \%$ of total activity.

SOD productivity, expressed as $\mathrm{U}_{\mathrm{SOD}} 1^{-1}$ of culture, were calculated and compared to summarize the influence of medium composition on both biomass yields and SOD specific activity. Bearing in mind the applicative outcomes of this study, we focused our attention on complex media. In YPD and YPL, SOD productivity was rather low and not significantly influenced by the presence of the $\mathrm{Cu}^{2+} / \mathrm{Zn}^{2+}$ supplement for both $K$. marxianus $\mathrm{L} 3$ and $K$. marxianus L3 (pYG-KmSOD1).

Finally, the results obtained on YPG were more promising, and the highest productivity was obtained with the recombinant strain $K$. marxianus L3(pYG-KmSOD1) grown in the complex medium with glycerol as carbon source, supplemented with $0.1 \mathrm{mM} \mathrm{CuCl} 2$ and $0.1 \mathrm{mM}$ $\mathrm{ZnCl}_{2}\left(\mathrm{YPG}^{\text {rec }}+8.8 \times 10^{5} \mathrm{U}_{\mathrm{SOD}} 1^{-1}\right.$; Fig. 4). 

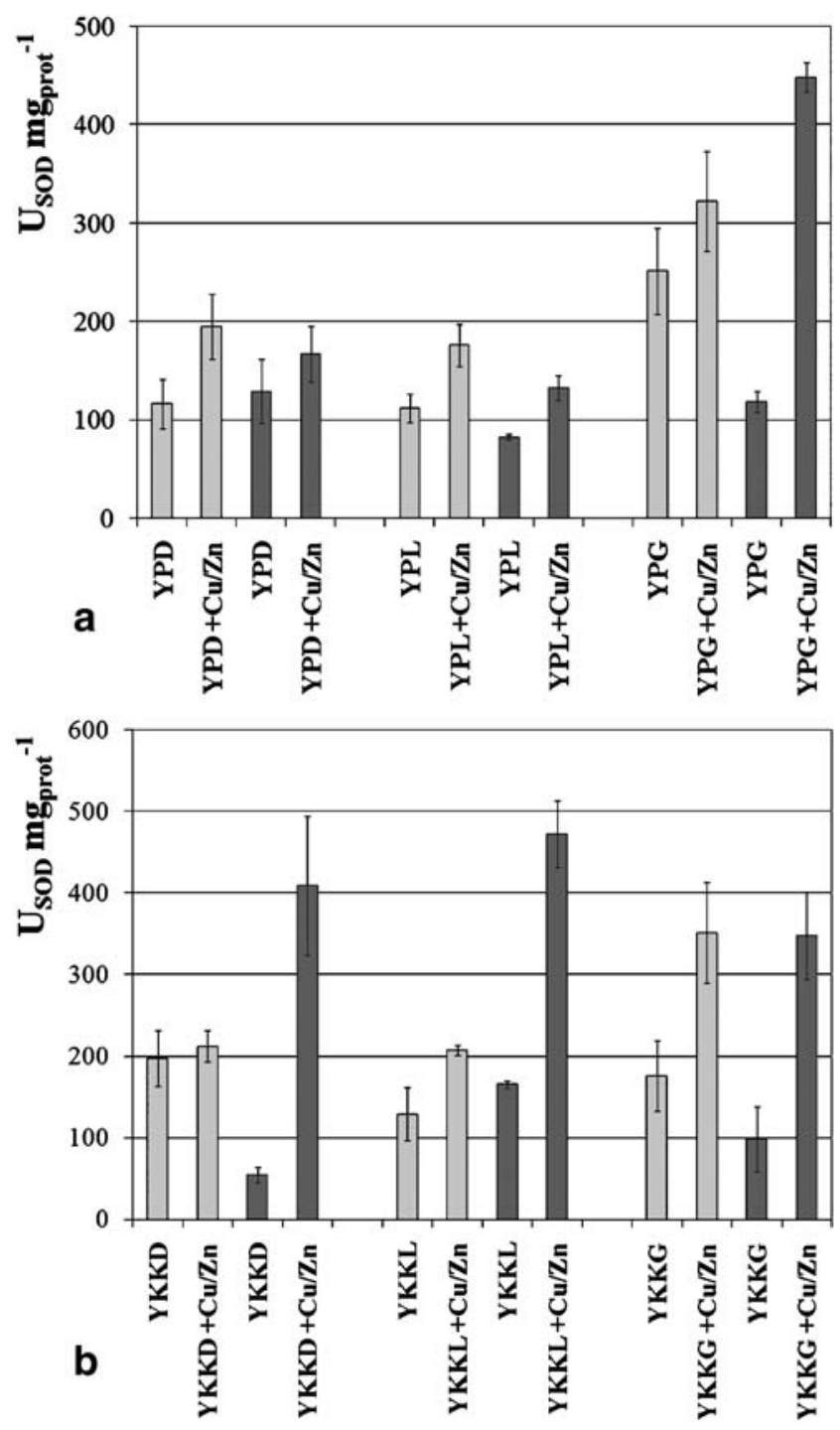

Fig. 3 Comparison of SOD specific activities $\left(\mathrm{U}_{\mathrm{SOD}} \mathrm{mg}_{\text {prot }}{ }^{-1}\right)$ from $K$. marxianus $\mathrm{L} 3$ and $K$. marxianus $\mathrm{L} 3(\mathrm{pYG}-\mathrm{KmSOD} 1)$ grown on various media and with supplement, measured by spectrophotometric assay. $+\mathrm{Cu} / \mathrm{Zn}$ Addition of $0.1 \mathrm{mM} \mathrm{CuCl} 2$ and $0.1 \mathrm{mM} \mathrm{ZnCl} 2$ in the culture media; gray bar wild-type strain; black bar recombinant strain harboring pYG-KmSOD1 plasmid. a YP-based (complex) media, b YKK-based (minimal) media

Fed-batch cultivations were carried out with the recombinant strain $K$. marxianus L3(pYG-KmSOD1) in the best performing culture medium (YPG supplemented with $\mathrm{Cu}^{2+}$ and $\mathrm{Zn}^{2+}$ ions). Experiments were carried out in triplicate, and the results presented are representative of the three fermentations (Fig. 5). The culture was initiated batchwise in the mineral-supplemented YPG medium. The ethanol pulse was applied after $47 \mathrm{~h}$, when biomass concentration was $9.3 \mathrm{DW} \mathrm{g} \mathrm{l}^{-1}$ and SOD specific activity was $221 \mathrm{U} \mathrm{mg}^{-1}$, corresponding to a $5.4 \times 10^{5} \mathrm{U}^{-1}$ productivity. The highest SOD specific activity ( $412 \mathrm{U} \mathrm{mg}^{-1}$ ) was observed $6 \mathrm{~h}$ after the induction of KmSOD1 expression. Once glycerol

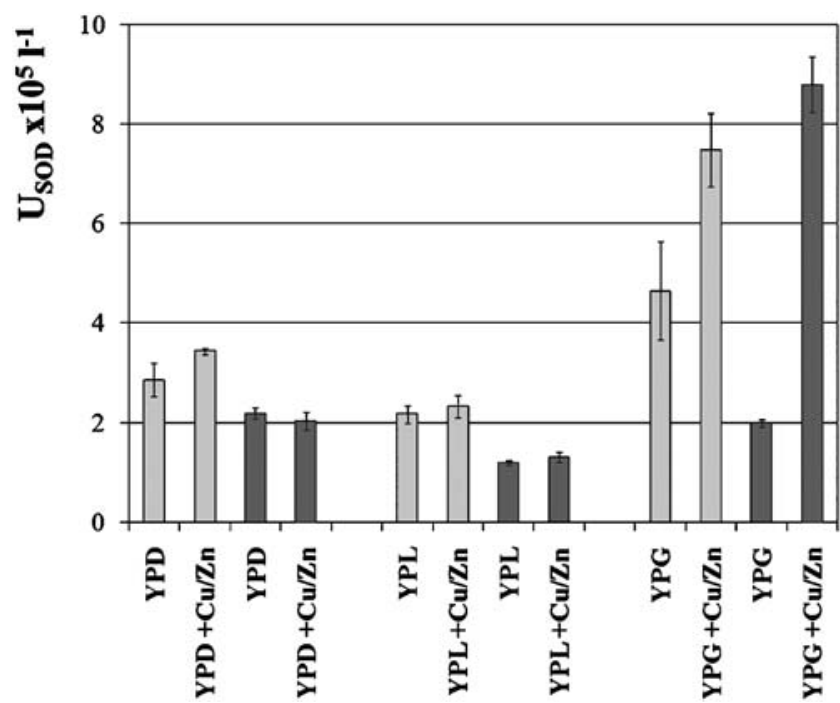

Fig. 4 SOD productivity $\left(\mathrm{U}_{\mathrm{SOD}} \times 10^{5} 1^{-1}\right)$ : performance comparison of control and recombinant strains on complex culture media. $+\mathrm{Cu} / \mathrm{Zn}$ Addition of $0.1 \mathrm{mM} \mathrm{CuCl} 2$ and $0.1 \mathrm{mM} \mathrm{ZnCl} 2$ in the culture media; gray bar wild-type strain; black bar recombinant strain harboring pYG-KmSOD1 plasmid

concentration decreased below $3 \mathrm{~g} \mathrm{l}^{-1}$, the culture was fed with glycerol, allowing biomass to increase up to 16.6 $\mathrm{DW} \mathrm{g} \mathrm{l}^{-1}$. Both the improved specific activity and biomass concentration enhanced SOD productivity up to $1.4 \times 10^{6} \mathrm{U}^{-1}$

\section{Discussion}

Superoxide dismutase is one of defense mechanisms that organisms developed for the detoxification from ROS and for preventing oxidative damages. This activity is at the base of increasing pharmaceutical and nutraceutical appli-

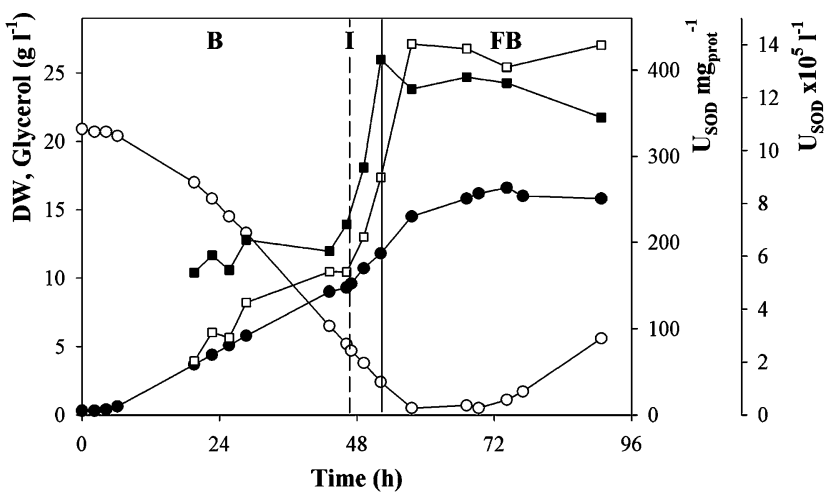

Fig. 5 K. marxianus L3(pYG-KmSOD1) fed-batch cultivation: filled circle biomass yield (g DW $\mathrm{l}^{-1}$ ); open circle glycerol $\left(\mathrm{g}^{-1}\right)$; filled square $\mathrm{SOD}$ specific activity $\left(\mathrm{U}_{\mathrm{SOD}} \mathrm{mg}_{\text {prot }}{ }^{-1}\right)$; open square $\mathrm{SOD}$ productivity $\left(\mathrm{U}_{\mathrm{SOD}} \times 10^{5} 1^{-1}\right)$. $B$ Batch phase; $F B$ fed-batch phase; $I$ ethanol pulse for induction of KmSOD expression 
cations. The aim of this work is to improve the knowledge on the $\mathrm{Cu} / \mathrm{Zn}$ SOD from $K$. marxianus $\mathrm{L} 3$, a promising dairy yeast that we proposed in an earlier paper for the fermentative production of SOD (Dellomonaco et al. 2007). Furthermore, the characterization of the gene coding for KmSod1p allowed molecular approaches for genetic engineering of the wild-type strain, aimed at improving SOD1 production.

In eukaryotes, the $\mathrm{Cu} / \mathrm{Zn}$ SOD mainly acquires copper through the chaperone CCS (copper chaperone for superoxide dismutase; Rae et al. 1999). Mammalian SOD1 present a CCS-independent secondary pathway of activation involving reduced glutathione, and reliant on the residues of serine S-143 and leucine L-145. S. cerevisiae enzyme can receive $\mathrm{Cu}$ only through $\mathrm{CCS}$, and this total dependence on CCS requires the presence of two residues of proline near the $\mathrm{C}$ terminus (P-143 and P-145; Carroll et al. 2004). Both $K$. marxianus and $K$. lactis Sod1 do not present any conservation of the indicated residues, and those positions are embedded in an otherwise exceptionally conserved region of the compared enzymes. This may suggest that, in Kluyveromyces yeasts, different mechanism(s) for cation interactions are present.

In this study, we compared recombinant and wild-type K. marxianus $\mathrm{L} 3$ strains performances, measuring biomass yields, SOD specific activity of cell-free extract, and SOD productivity. Effects exerted by culture media composition were registered by changing from complete media to minimal synthetic media, by adding three different carbon sources (glucose, lactose, and glycerol) and by varying the availability of the metal cofactors $\mathrm{Cu}^{2+}$ and $\mathrm{Zn}^{2+}$ with a supplement of $0.1 \mathrm{mM}$ of each ion in the cultures.

Surprisingly, K. marxianus L3 grew in batch cultures with similar biomass yields both on minimal synthetic and complete medium; in addition, no significant differences were observed on the three carbon source tested: glucose, lactose, and glycerol. Despite the fact that glycerol is a respiratory carbon source for yeast cells and it was expected that a sustained oxidative stress could occur in cells growing on this substrate, it turned out to be a good carbon source for $K$. marxianus L3, similar to fermentable sugars. Furthermore, the presence of recombinant plasmid pYGKmSOD1 and of the supplement of $0.1 \mathrm{mM} \mathrm{Cu}^{2+}$ and $0.1 \mathrm{mM} \mathrm{Zn}^{2+}$ ions, which are 50 times lower with respect to the minimal inhibitory concentrations of this strain (data not shown), did not significantly affect biomass yields.

On the other hand, the addition of the $\mathrm{Cu}^{2+} / \mathrm{Zn}^{2+}$ supplement to the culture media noticeably increased SOD specific activity and SOD productivity, both in the wild-type and in the recombinant strains. The overexpression of recombinant KmSOD1 leads to a real increase of the specific activity only in presence of the supplement of $\mathrm{Cu}^{2+}$ and $\mathrm{Zn}^{2+}$ ions.
For recombinant strain cultures, Western-blot analysis indicated a clear increase of SOD1 protein in the presence of plasmid pYG-KmSOD1, as compared to the control. Perhaps, the overexpression conditions produced an excess of recombinant protein that was not activated to the corresponding holoenzyme; this could be due to a limiting supply of $\mathrm{Cu}^{2+}$ and $\mathrm{Zn}^{2+}$ ions under the culture conditions studied. This is supported by the observation that increasing metal factor availability in the culture media resulted in enhanced SOD activity.

Recently, SOD1 gene of $S$. cerevisiae was expressed in Pichia pastoris to obtain a recombinant SOD production (Yu 2007). However, the specific activity, determined on total cell extracts, did not favorably compare with the one obtained by the $K$. marxianus recombinant strain $\left(83 \mathrm{U} \mathrm{mg}^{-1}\right.$ in $P$. pastoris vs $500 \mathrm{U} \mathrm{mg}-1$ in $K$. marxianus). The difference could be due at least in part to the $P$. pastoris expression system and in part to a limited availability of metal cofactors for the SOD enzyme produced by using standard media. Moreover, even the $K$. marxianus L3 untransformed strain showed threefold more SOD specific activity as compared to $P$. pastoris counterpart, suggesting that $K$. marxianus L3 overexpressing KmSOD1 could indeed represent a good candidate for large-scale SOD production.

Metal ions are highly toxic due to their redox capabilities, and their concentration and availability in the cell compartments is tightly controlled. In the yeast $S$. cerevisiae, $\mathrm{Cu}^{2+}$ ions enter the cell via the high-affinity uptake protein Ctrlp (Dancis et al. 1994). The specific chaperones CCS, Cox17p, and Atx1p are involved in the distribution of $\mathrm{Cu}^{2+}$ to intracellular proteins and to the secretory pathway compartments, respectively (Culotta et al. 1997; Field et al. 2002; Glerum et al. 1996; Lin and Culotta 1995). In the meantime, the sequestration of excess $\mathrm{Cu}^{2+}$ by metallothioneins prevents cellular damage (Butt et al. 1984; Rae et al. 1999). Future investigations aimed at studying the expression levels of those proteins in different culture conditions may help to explain the values of SOD activity observed in $K$. marxianus L3 cultures.

The results of this study provide a better knowledge of K. marxianus $\mathrm{L} 3 \mathrm{Cu} / \mathrm{Zn}$ superoxide dismutase. The culture parameters that positively affect active enzyme production were identified, the best performing culture conditions were positively applied to a laboratory scale fed-batch process, and a first promising indication for a biotechnological production of recombinant $K$. marxianus SOD was obtained.

Acknowledgments This study was partially supported by PRIN 2006 research program: "Yeast as sources of biodiversity for the production of molecules of agro-alimentary and pharmaceutical interest" and by Ateneo research funding La Sapienza 2007. 


\section{References}

Bender JP, Mazutti MA, de Oliveira D, Di Luccio M, Treichel H (2006) Inulinase production by Kluyveromyces marxianus NRRL Y-7571 using solid state fermentation. Appl Biochem Biotechnol 129-132:951-958

Butt TR, Sternberg EJ, Gorman JA, Clark P, Hamer D, Rosenberg M, Crooke ST (1984) Copper metallothionein of yeast, structure of the gene, and regulation of expression. Proc Natl Acad Sci U S A 81:3332-3336

Campanella JJ, Bitincka L, Smalley J (2003) MatGAT: an application that generates similarity/identity matrices using protein or DNA sequences. BMC Bioinformatics 4:29

Carroll MC, Girouard JB, Ulloa JL, Subramaniam JR, Wong PC, Valentine JS, Culotta VC (2004) Mechanisms for activating $\mathrm{Cu}$ and $\mathrm{Zn}$-containing superoxide dismutase in the absence of the CCS Cu chaperone. Proc Natl Acad Sci U S A 101:5964-5969

Chen XJ, Saliola M, Falcone C, Bianchi MM, Fukuhara H (1986) Sequence organization of the circular plasmid pKD1 from the yeast Kluyveromyces drosophilarum. Nucleic Acids Res 14:4471-4481

Corvo ML, Jorge JC, van't HR, Cruz ME, Crommelin DJ, Storm G (2002) Superoxide dismutase entrapped in long-circulating liposomes: formulation design and therapeutic activity in rat adjuvant arthritis. Biochim Biophys Acta 1564:227-236

Culotta VC, Klomp LW, Strain J, Casareno RL, Krems B, Gitlin JD (1997) The copper chaperone for superoxide dismutase. J Biol Chem 272:23469-23472

Dancis A, Haile D, Yuan DS, Klausner RD (1994) The Saccharomyces cerevisiae copper transport protein (Ctrlp). Biochemical characterization, regulation by copper, and physiologic role in copper uptake. J Biol Chem 269:25660-25667

Dellomonaco C, Amaretti A, Zanoni S, Pompei A, Matteuzzi D, Rossi M (2007) Fermentative production of superoxide dismutase with Kluyveromyces marxianus. J Ind Microbiol Biotechnol 34:27-34

Emerit J, Samuel D, Pavio N (2006) Cu-Zn super oxide dismutase as a potential antifibrotic drug for hepatitis $\mathrm{C}$ related fibrosis. Biomed Pharmacother 60:1-4

Field LS, Luk E, Culotta VC (2002) Copper chaperones: personal escorts for metal ions. J Bioenerg Biomembr 34:373-379

Fonseca GG, Gombert AK, Heinzle E, Wittmann C (2007) Physiology of the yeast Kluyveromyces marxianus during batch and chemostat cultures with glucose as the sole carbon source. FEMS Yeast Res $7: 422-435$

Fridovich I (1978) The biology of oxygen radicals. Science 201:875880

Fridovich I (1998) Oxygen toxicity: a radical explanation. J Exp Biol 201:1203-1209

Glerum DM, Shtanko A, Tzagoloff A (1996) Characterization of COX17, a yeast gene involved in copper metabolism and assembly of cytochrome oxidase. J Biol Chem 271:1450414509

Goulielmos GN, Arhontaki K, Eliopoulos E, Tserpistali K, Tsakas S, Loukas M (2003) Drosophila $\mathrm{Cu}, \mathrm{Zn}$ superoxide dismutase gene confers resistance to paraquat in Escherichia coli. Biochem Biophys Res Commun 308:433-438

Harris N, Bachler M, Costa V, Mollapour M, Moradas-Ferreira P, Piper PW (2005) Overexpressed Sod1p acts either to reduce or to increase the lifespans and stress resistance of yeast, depending on whether it is $\mathrm{Cu}(2+)$-deficient or an active $\mathrm{Cu}, \mathrm{Zn}$-superoxide dismutase. Aging Cell 4:41-52

Hart PJ, Balbirnie MM, Ogihara NL, Nersissian AM, Weiss MS, Valentine JS, Eisenberg D (1999) A structure-based mechanism for copper-zinc superoxide dismutase. Biochemistry 38:21672178

Laemmli UK (1970) Cleavage of structural proteins during the assembly of the head of bacteriophage T4. Nature 227:680-685

Limtong S, Sringiew C, Yongmanitchai W (2007) Production of fuel ethanol at high temperature from sugar cane juice by a newly isolated Kluyveromyces marxianus. Bioresour Technol 98:3367-3374

Lin SJ, Culotta VC (1995) The ATX1 gene of Saccharomyces cerevisiae encodes a small metal homeostasis factor that protects cells against reactive oxygen toxicity. Proc Natl Acad Sci U S A 92:3784-3788

Lowry OH, Rosebrough NJ, Farr AL, Randall RJ (1951) Protein measurement with the Folin phenol reagent. J Biol Chem 193:265-275

Luk E, Yang M, Jensen LT, Bourbonnais Y, Culotta VC (2005) Manganese activation of superoxide dismutase 2 in the mitochondria of Saccharomyces cerevisiae. J Biol Chem 280:22715-22720

Masoud W, Jespersen L (2006) Pectin degrading enzymes in yeasts involved in fermentation of Coffea arabica in East Africa. Int $\mathrm{J}$ Food Microbiol 110:291-296

McCord JM, Fridovich I (1969) Superoxide dismutase. An enzymic function for erythrocuprein (hemocuprein). J Biol Chem 244:6049-6055

Moradas-Ferreira P, Costa V, Piper P, Mager W (1996) The molecular defences against reactive oxygen species in yeast. Mol Microbiol 19:651-658

Nishikawa M, Nagatomi H, Nishijima M, Ohira G, Chang BJ, Sato E, Inoue $M$ (2001) Targeting superoxide dismutase to renal proximal tubule cells inhibits nephrotoxicity of cisplatin and increases the survival of cancer-bearing mice. Cancer Lett 171:133-138

Rae TD, Schmidt PJ, Pufahl RA, Culotta VC, O’Halloran TV (1999) Undetectable intracellular free copper: the requirement of a copper chaperone for superoxide dismutase. Science 284:805-808

Saliola M, Mazzoni C, Solimando N, Crisa A, Falcone C, Jung G, Fleer R (1999) Use of the KlADH4 promoter for ethanoldependent production of recombinant human serum albumin in Kluyveromyces lactis. Appl Environ Microbiol 65:53-60

Sambrook J, Fritsch EF, Maniatis T (2001) Molecular Cloning: a Laboratory Manual. Cold Spring Harbor Laboratory Press, Cold Spring Harbor, New York

Sherman F, Fink GR, Hicks JB (1986) Methods in Yeast Genetics: A Laboratory Manual. Cold Spring Harbor Laboratory Press, Cold Spring Harbor, New York

Sturtz LA, Diekert K, Jensen LT, Lill R, Culotta VC (2001) A fraction of yeast $\mathrm{Cu}, \mathrm{Zn}$-superoxide dismutase and its metallochaperone, $\mathrm{CCS}$, localize to the intermembrane space of mitochondria. A physiological role for SOD1 in guarding against mitochondrial oxidative damage. J Biol Chem 276:38084-38089

Taylor WR (1986) The classification of amino acid conservation. J Theor Biol 119:205-218

Vorauer-Uhl K, Furnschlief E, Wagner A, Ferko B, Katinger H (2001) Topically applied liposome encapsulated superoxide dismutase reduces postburn wound size and edema formation. Eur J Pharm Sci 14:63-67

Wesolowsky-Louvel M, Breunig KD, Fukuhara H (1996) Kluyveromyces lactis. In: Wolf K (ed) Nonconventional Yeasts in Biotechnology. Springer, Berlin, pp 139-201

Wink DA, Mitchell JB (1998) Chemical biology of nitric oxide: Insights into regulatory, cytotoxic, and cytoprotective mechanisms of nitric oxide. Free Radic Biol Med 25:434-456

Yabe Y, Kobayashi N, Nishihashi T, Takahashi R, Nishikawa M, Takakura Y, Hashida M (2001) Prevention of neutrophil-mediated hepatic ischemia/reperfusion injury by superoxide dismutase and catalase derivatives. J Pharmacol Exp Ther 298:894-899 
Yoo HY, Kim SS, Rho HM (1999) Overexpression and simple purification of human superoxide dismutase (SOD1) in yeast and its resistance to oxidative stress. J Biotechnol 68:29-35

Yu P (2007) A new approach to the production of the recombinant SOD protein by methylotrophic Pichia pastoris. Appl Microbiol Biotech 74:93-98
Yunoki M, Kawauchi M, Ukita N, Sugiura T, Ohmoto T (2003) Effects of lecithinized superoxide dismutase on neuronal cell loss in CA3 hippocampus after traumatic brain injury in rats. Surg Neurol 59:156-160

Zhang Y, Wang JZ, Wu YJ, Li WG (2002) Anti-inflammatory effect of recombinant human superoxide dismutase in rats and mice and its mechanism. Acta Pharmacol Sin 23:439-444 